\title{
PEMANFAATAN VIDEO YOUTUBE DALAM MENINGKATKAN MOTIVASI BELAJAR SISWA INSAN LITERA
}

\author{
Aisyah Farhatunnisya \\ IKIP Siliwangi - Cimahi - Jawa Barat - Indonesia \\ farhatunnisyaa@gmail.com \\ Received: Januari, 2020; Accepted: Mei, 2020
}

\begin{abstract}
This research is motivated by the fact about the low motivation to learn in students and the rise of the use of YouTube among students or adolescents. This research was conducted at the clear saguling foundation, a foundation that engages in social affairs and helps the welfare of the community around the Citarum river located in Jl. Cianjur, cihampelas village, west bandung district in this foundation which is related to what is meant by human beings in litera. The cornerstone of the theory used in this study is the theory of the use of YouTube and learning motivation theory. The purpose of this study is to study the motivation of YouTube applications to increase student motivation. The method used is to use qualitative methods with descriptive methods. The technique of receiving data through participant observation and interviews. Litera human students with a total of 11 students and 11 respondents from the respondents selected five people as a research sample. litera
\end{abstract}

Keywords: use of youtube, motivation, students

\begin{abstract}
Abstrak
Penelitian ini di latar belakangi oleh adanya fakta tentang rendahnya motivasi belajar pada siswa dan maraknya penggunaan youtube di kalangan siswa atau remaja.Penelitian ini dilakukan di yayasan bening saguling foundation yayasan yang bergerak di bidang sosial dan bertujuan untuk mensejahterakan masyarakat sekitar sungai citarum yang terletak di jl.babakan cianjur desa cihampelas kabupaten bandung barat di yayasan tersebut mempunyai sekolah yang berbasis alam yang bernama insan litera.Landasan teori yang digunakan dalam penelitian ini yaitu teori pemanfaatan youtube dan teori motivasi belajar.Tujuan dari penelitian ini yaitu untuk mengetahui pengaruh aplikasi youtube dapat meningkatkan motivasi belajar siswa.Metodeyang di gunakan yaitu dengan pendekatan kualitatif dengan metode deskriptif.Teknik pengumpulan data melalui observasi dan dan menyebarkan kuosioner kepada para partisipan yaitu siswa insan litera dengan jumlah siswa 11 orang dan dari responden sebanyak 11 orang di pilih lima orang sebagai sampel penelitianHasil dari penelitian ini yaitu dapat diketahui bahwa pemanfaatanvideo youtube dapat meningkatan motivasi belajar siswa insan litera.
\end{abstract}

Kata Kunci: pemanfaatan youtube,motivasi belajar,siswa

How to Cite: Farhatunnisya, A. (2020). Pemanfaatan Video Youtube Dalam Meningkatkan Motivasi Belajar Siswa Insan Litera. Comm-Edu (Community Education Journal) 3 (2), 109-114.

\section{PENDAHULUAN}

Pada era globalisasi ini perkembangan informasi dan sumber informasi berkembang sangat pesat apalagi di tambah dengan dukungan teknologi yang semakin maju dan canggih yang akan mempermudah pekerjaan manusia, selain itu teknologi tidak hanya di gunakan oleh orang dewasa saja tetapi berbagai ka langan menggunakannya mulai dari orang dewasa sampe anak kecil pun sekarang mereka sudah biasa memakai teknologi untuk berbagai kepentingan bahkan berbagai instansi-instansi dan pendidikan mulai menggunakan teknologi untuk sistem dan 
pembelajaran mereka, dan salah satu teknologi informasi yang paling banyak di gunakan salah satunya aplikasi youtube.

Youtube di resmikan pada tahun 2005 dan didirikan oleh tiga mantan karyawan paypal yaitu Chad Hurley, Steve Chen, Jawed Karim. Kemudian aplikasi Youtube dibeli oleh perusahaan Google dan diperkenalkan kembali pada tahun 2006. Berdasarkan penelitian yang dilakukan oleh hootsuite sangat jelas bahwa Youtube sangat digemari oleh orang-orag di berbagai negara khususnya masyarakat Indonesia di kalangan remaja, kegunaan Youtobe menurut (Putra \& Patmaningrum, 2018) yaitu sebagai perantara bagi orang-orang untuk saling berhubungan, memberikan informasi dan menginspirasi orang lain di seluruh dunia, serta sebagai aplikasi pemasaran produk yang dimiliki pengguna youtube bagi pembuat konten maupun iklan, baik yang besar maupun kecil.

Melalui konten positif yang ada di aplikasi youtube bisa menjadi salah satu media pembelajaran. Menurut said A.M, Rusdi, Muhammad Y, 2008 dalam (Mulyaningsih, 2014) menunjukkan bahwa pada tahun 2007 sampai 2008 prestasi belajar siswa di Indonesia belum maksimal, karena daya serap siswa baru mencapai 60,93\%, dan siswa yang mendapat nilai kurang dari 65 mencapai 39,07\%.,dari data tersebut dapat disimpulkan bahwa rendahnya prestasi yang di capai dapat juga di sebabkan oleh rendahnya motivasi belajar. Menurut Clayton Alderfer dalam (Syaifudin, Yuliani, \& Oktiwanti, 2018)Motivasi belajar berkaitan juga dalam melakukan kegiatan belajar yang didorong oleh keinginan siswa untuk mencapai prestasi atau hasil belajar sebaik mungkin. Adapun faktor-faktor yang mempengaruhi motivas belajar menurut (Syamsu, 2009) motivasi belajar dapat timbul karena faktor internal dan eksternal: 1) Faktor internal terdiri dari faktor fisik dan faktor psikologis. a)Faktor fisik merupakan faktor yang mempengaruhi dari tubuh dan penampilan individu. Seperti kesehatan yang mencakup nutrisi dan fungsi-fungsi fisik terutama panca indera. b) Faktor Psikologis merupakan faktor yang di lihat dari berbagai aspek yang mendorong serta menghambat kegiatan proses belajar pada siswa. Faktor ini menyangkut kondisi mental siswa.2) Faktor Eksternal terbagi menjadi dua aspek yaitu : a) Faktor Sosial Merupakan faktor yang berhubungan dengan manusia maupun lingkungan sekitar siswa. Faktor sosial terdiri dari guru/tutor, orang tua, tetangga, teman dan lain-lain. b) Faktor Non-sosial yaitu keadaan atau kondisi fisik di sekitar siswa maupun lingkungan alam seperti keadaan udara cuaca panas atau dingin, waktu pagi, siang, atau malam, tempat sepi, bising, atau kualitas sekolah tempat belajar, dan fasilitas belajar sarana dan prasarana.

Dari pemaparan diatas menurunnya motivasi belajar ini selaras dengan permasalahan yang terjadi di LSM bening saguling di antaranya yaitu, media belajar yang kurang menarik seingga kegiatan belajar mengajar terkesan monoton di tambah lagi kurangnya dorongan dari orang terdekat, selain dua faktor eksternal tersebut adapun faktor internal yang menyebabkan menurunnya motivasi belajar yaitu kurangnya kepercayaan diri dan tidak mampu beradaptasi dengan lingkungan sekolah. Maka dari itu guru menciptakan inovasi baru dengan memanfaatkan aplikasi youtube guna meningkatkan motivasi belajar dengan cara memberikan film edukasi bagi siswa. 


\section{LANDASAN TEORI}

\section{Jejaring sosial melalui aplikasi youtube}

Jejaring sosial adalah layanan daring (online) yang penggunaanya tidak hanya memakai tetapi juga bisa berpartisipasi dalam membuat,mengomentari dan menyebarkan beragam konten seperti teks, gambar, audio atau video. Salah satunya yaitu aplikasi youtube, youtube menurut (Putra \& Patmaningrum, 2018) merupakan sebuah platform untuk memublikasikan video, platform ini dapat diakses oleh semua orang di negara manapun. Youtube di resmikan pada tahun 2005 dan didirikan oleh tiga mantan karyawan paypal yaitu Chad Hurley, Steve Chen, Jawed Karim. Kemudian aplikasi Youtube dibeli oleh perusahaan Google dan dipublikasikan kembali pada tahun 2006. Kegunaan youtube yaitu sebagai perantara bagi orang-orang untuk saling berhubungan, memberikan informasi dan menginspirasi orang lain di seluruh dunia, serta sebagai aplikasi pemasaran produk yang dimiliki pengguna youtube bagi pembuat konten maupun iklan, baik yang besar maupun kecil.

\section{Motivasi belajar}

Motivasi adalah suatu usaha sadar yang mengarahkan, menggerakan dan menjaga sikap seseorang dengan demikian ia terdorong untuk melakukan sesuatu agar mencapai hasil atau tujuan tertentu. (Hamdu \& Agustina, 2011)

Menurut Clayton Alderfer dalam (Syaifudin, Yuliani, \& Oktiwanti, 2018) Motivasi belajar Motivasi belajar berkaitan juga dalam melakukan kegiatan belajar yang didorong oleh keinginan siswa untuk mencapai prestasi atau hasil belajar sebaik mungkin.

Pada proses pembelajaran motivasi dapat dikaitkan sebagai komponen daya penggerak yang ada di dalam diri siswa yang menimbulkan kegiatan belajar, memberikan arah pada kegiatan belajar dan memenuhi kelangsungan dari kegiatan belajar, sehingga tujuan yang diinginkan oleh peserta belajar itu dapat tercapai Sadirman 2000 dalam (Syarif, 2012). Pada Teori Motivasi abraham maslow dalam (Prihartanta, 2015) mengemukakan bahwa pada dasarnya semua manusia memiliki kebutuhan pokok. Yaitu ada 5 tingkatan yang berbentuk piramid dan dikenal dengan sebutan hirarki kebutuhan maslow, dimulai dari kebutuhan biologis dasar sampai motif psikologis yang lebih kompleks; yang hanya akan penting setelah kebutuhan dasar terpenuhi. Kebutuhan pada suatu peringkat paling tidak harus terpenuhi sebagian sebelum kebutuhan pada peringkat berikutnya menjadi penentu tindakan yang penting: a) Kebutuhan fisiologis yaitu rasa lapar, rasa haus, dan sebagainya; b) Kebutuhan rasa aman yaitu seseorang yang merasakan rasa aman dan terlindungi serta jauh dari bahaya; c) Kebutuhan akan rasa cinta dan rasa memiliki; d) Kebutuhan akan penghargaan dalam berprestasi, berkompetensi, dan mendapatkan dukungan serta pengakuan; e) Kebutuhan aktualisasi diri mengetahui, memahami, dan menjelajahi; kebutuhan estetik: keserasian, keteraturan, dan keindahan; kebutuhan aktualisasi diri: mendapatkan kepuasan diri dan menyadari potensinya.

\section{METODE PENELITIAN}

Berdasarkan permasalahan yang diteliti metode yang digunakan dalam penelitian ini adalah metode deskriptif dengan pendekatan kualitatif. (Mashuri \& zainudin, 2008) menjelaskan bahwa metode deskriptif merupakan penelitian yang memberi gambaran secara cermat mengenai individu, keadaan kondisi masyarakat sekitar.Menurut (Sugiyono, 2012) mendeskripsikan bahwa Metode penelitian kualitatif merupakan metode penelitian yang berlandaskan pada filsafat positivisme, digunakan untuk meneliti pada kondisi obyek yang alamiah, (sebagai lawannya adalah eksperimen) dimana peneliti adalah sebagai instrumen 
kunci, teknik pengumpulan data dilakukan secara triangulasi (gabungan), analisis dan bersifat induktif/ kualitatif, dan hasil penelitian kualitatif lebih menekankan makna dari pada generalisasi.

Metode deskriptif disini yaitu peneliti ,menggambarkan tentang hasil dari penggunaan youtube terhadap peningkatan motivasi belajar siswa di bening saguling foundation. Teknik pengumpulan data melalui wawancara dan observasi kepada para partisipan yaitu siswa insan litera dengan jumlah siswa 11 orang dan dari responden sebanyak 11 orang di pilih lima orang sebagai sampel penelitian alasanya mengambil di LSM bening saguling karna di usia mereka yang masih produktif dan masih mudah di arahkan menjadi pribadi yang lebih baik. Lokasi penelitian ini terletak di jl.babakan cianjur desa cihampelas kabupten bandung barat. Yaitu dengan tahapan yang pertama perencanaan pada tahap ini peneliti mulai merencanakan tentang persiapan-persiapan untuk meneliti yaitu dengan membuat perencanaan, membuat instrument wawancara untuk diberikan kepada warga belajar atau siswa setelah itu peneliti mulai mengobservasi tempat penelitian,tahap kedua yaitu pelaksanaan pada tahap ini peneliti mulai melaksanakan penelitian yaitu dengan menyiapkan film pendek untuk di tonton oleh para siswa sebanyak lima kali pertemuan film tersebut bertema pendidikan yang di dalamnya terdapat cerita untuk meningkatkan motivasi belajar siswa dan tahap ketiga yaitu evaluasi setelah menonton video edukasi peneliti mewawancara partisipan atau siswa dengan menanyakan bagaimana kesan mereka serta apa yang dapat di ambil dari film yang mereka tonton dan dari situ peneliti dapat melihat hasil dari penggunaan youtube dalam meningkatan motivasi belajar.

\section{HASIL DAN PEMBAHASAN \\ Hasil}

Berdasarkan penelitan yang di lakukan ,di temukan hasil sebagai berikut :

\section{Pertama yaitu kondisi motivasi belajar siswa sebelum penggunaan media youtube}

Sebelum adanya penggunaan media youtube sebagai media belajar, motivasi mereka sangat rendah menyebabkan suasana ketika proses kegiatan belajar mengejar berlangsung tidak kondusif dan respon siswa cenderung pasif ketika di ajak berdiskusi oleh guru. Setelah adanya pemanfaatan youtube sebagai media belajar terlihat adanya perbedaan yang signifikan yaitu siswa menjadi lebih aktif dan mereka lebih semangat lagi untuk datang kesekolah.

\section{Kedua yaitu proses peningkatan motivasi belajar siswa dengan menggunakan media youtube}

Proses awal pembelajaran menggunakan media youtube di tentukan oleh guru sebanyak 5 kali pertemuan dengan konten film edukasi yang berbeda-beda di setiap pertemuannya. Proses peningkatan motivasinya siswa lebih mudah menerima materi yang di berikan oleh guru kepada siswa serta siswa terlihat lebih antusias dalam proses pembelajaran sehingga menimbulkan rasa keingin tahuan yang besar yang mampu di manfaatkan oleh guru untuk mengasah pola piker mereka yang lebih kritis.

\section{Ketiga yaitu faktor-faktor penghambat motivasi belajar siswa}

faktor penghambat dalam pengguanaan media youtub yaitu Kurangnya fasilitas yang memadai,kurangnya tenaga pendidik untuk mengajar mereka,buruknya jaringan koneksi yang menghambat proses pembelajaran,pemasukan sumber dana yang tidak menentu karna hanya mengandalkan sumber dana pribadi. 


\section{Pembahasan}

Pembahasan yang pertama yaitu mengenai kondisi belajar siswa sebelum penggunaan media yaitu Sebelum adanya penggunaan media youtube sebagai media belajar, motivasi mereka sangat rendah menyebabkan suasana ketika proses kegiatan belajar mengejar berlangsung tidak kondusif dan respon siswa cenderung pasif ketika di ajak berdiskusi oleh guru. Keadaan tersebut disebabkan oleh kurang menariknya pembelajaran.Setelah adanya pemanfaatan youtube sebagai media belajar terlihat adanya perbedaan yang signifikan yaitu siswa menjadi lebih aktif dan mereka lebih semangat lagi untuk datang kesekolah. Maka dari itu dibutuhkan dorongan dari eksternal maupun dari internal mereka. contoh dorongan dari eksternal yaitu dukungan keluarga khususnya orang tua yang memiliki peran untuk terus mendampingi mereka ketika mereka sudah di luar lingkungan sekolah, lingkup pertemanan yang positif mampu mendorong mereka dalam perubahan tingkah laku maupun pola pikir mereka.selain faktor eksternal, faktor internal juga menjagi hal yang penting seperti dorongan dalam diri mereka untuk mau berubah,keluar dari zona nyaman mereka dan mulai mengeksplor dunia luar hal ini selaras dengan pendapat yang di kemukakan oleh Clayton Alderfer dalam (Syaifudin, Yuliani, \& Oktiwanti, 2018) Motivasi belajar berkaitan juga dalam melakukan kegiatan belajar yang didorong oleh keinginan siswa untuk mencapai prestasi atau hasil belajar sebaik mungkin.

Pembahasan yang kedua yaitu proses peningkatan motivasi belajar siswa dengan menggunakan media youtube.Proses awal pembelajaran menggunakan media youtube di tentukan oleh guru sebanyak 5 kali pertemuan dengan konten film edukasi yang berbeda-beda di setiap pertemuannya. Proses peningkatan motivasinya siswa lebih mudah menerima materi yang di berikan oleh guru kepada siswa serta siswa terlihat lebih antusias dalam proses pembelajaran sehingga menimbulkan rasa keingin tahuan yang besar yang mampu di manfaatkan oleh guru untuk mengasah pola pikir mereka untuk lebih kritis. Maka dari itu pertemuan di rancang oleh guru se intens mungkin agar motivasi siswa dalam proses pembelajaran mampu terbentuk dan di pertahankan sampai tercapainya tujuan yag ingin di capai selaras dengan pendapat Sadirman2000 dalam (Syarif, 2012)menyatakan Pada proses pembelajaran motivasi dapat dikaitkan sebagai komponen daya penggerak yang ada di dalam diri siswa yang menimbulkan kegiatan belajar, memberikan arah pada kegiatan belajar dan memenuhi kelangsungan dari kegiatan belajar, sehingga tujuan yang diinginkan oleh peserta belajar itu dapat tercapai.

Pembahasan yang ketiga yaitu faktor-faktor penghambat motivasi belajar siswa. Faktor penghambat dalam pengguanaan media aplikasi youtube yaitu Kurangnya fasilitas yang memadai,kurangnya tenaga pendidik untuk mengajar mereka,buruknya jaringan koneksi yang menghambat proses pembelajaran, dan pemasukan sumber dana yang tidak menentu karna hanya mengandalkan sumber dana pribadi. Seperti faktor-faktor yang mempengaruhi motivas belajar menurut (Syamsu, 2009) motivasi belajar dapat timbul karena faktor internal dan eksternal: 1) Faktor internal terdiri dari faktor fisik dan faktor psikologis. a)Faktor fisik merupakan faktor yang mempengaruhi dari tubuh dan penampilan individu. Seperti kesehatan yang mencakup nutrisi dan fungsi-fungsi fisik terutama panca indera. b) Faktor Psikologis merupakan faktor yang di lihat dari berbagai aspek yang mendorong serta menghambat kegiatan proses belajar pada siswa. Faktor ini menyangkut kondisi mental siswa.2) Faktor Eksternal terbagi menjadi dua aspek yaitu : a) Faktor Sosial Merupakan faktor yang berhubungan dengan manusia maupun lingkungan sekitar siswa. Faktor sosial terdiri dari guru/tutor, orang tua, tetangga, teman dan lain-lain. b) Faktor Non-sosial yaitu keadaan atau kondisi fisik di sekitar siswa maupun lingkungan alam seperti keadaan udara cuaca panas atau 
114 Farhatunnisya, Pemanfaatan Video Youtube Dalam Meningkatkan Motivasi Belajar Siswa Insan Litera

dingin, waktu pagi, siang, atau malam, tempat sepi, bising, atau kualitas sekolah tempat belajar, dan fasilitas belajar sarana dan prasarana.

Berdasarkan pembahasan diatas dapat disimpulkan faktor penghambat motivasi belajar ini harus terpenuhi supaya tujuan pembelajaran dapat tercapai mampu di pertahankan.

\section{KESIMPULAN}

Berdasarkan pemaparan dan hasil penelitian yang telah penulis uraian diatas maka dapat di ambil kesimpulan bahwa pemanfaatan media aplikasi youtube dalam meningkatkan motivasi siswa insan litera perlu adanya pihak yang turut membimbing dan mengarahkan mereka agar mampu termotivasi untuk belajar. Melalui film edukasi yang di berikan siswa mampu mengambil pesan moral dan pengetahuan yang ada di film tersebut sehingga bukan hanya dapat meningkatkan motivasi saja tetapi mampu mengubah sikap dan pola pikir siswa setelah menonton film edukasi tersebut.

\section{DAFTAR PUSTAKA}

Hamdu, G., \& Agustina, L. (2011). pengaruh motivasi belajar siswa terhadap prestasi belajar IPA di sekolah dasar. jurnal pendidikan Vol. 12 (1), 83-85.

Mashuri, \& zainudin, M. (2008). metodologi penelitian : pendekatan praktis dan aplikatif. Bandung: Refika Aditama.

Mulyaningsih, E. I. (2014). PENGARUH INTERAKSI SOSIAL KELUARGA, MOTIVASI BELAJAR, DAN KEMANDIRIAN BELAJAR TERHADAP PRESTASI BELAJAR. jurnal pendidikan dan kebudayaan vol 20 (4), 441-449.

Prihartanta, W. (2015). TEORI-TEORI MOTIVASI. jurnal adabiya vol.1 no.83, 1-11. Retrieved from academia.edu.

Putra, A., \& Patmaningrum, D. A. (2018). PENGARUH YOUTUBE DI SMARTPHONE TERHADAP PERKEMBANGAN KOMUNIKASI INTERPERSONAL ANAK. jurnal penelitian komunikasi vol 21 (2), 169-171.

Sugiyono. (2012). metode penelitian bisnis. Bandung: CV alfabeta.

Syaifudin, Yuliani, L., \& Oktiwanti, L. (2018). PEMBERIAN KARTU INDONESIA PINTAR (KIP) DALAM UPAYA MENINGKATKAN MOTIVASI BELAJAR BAGI PESERTA DIDIK DI PKBM GEMA PADA PENDIDIKAN DI PKBM GEMA PADA PENDIDIKAN KESETARAAN PROGRAM PAKET B DAN C KECAMATAN TAWANG KOTA. jurnal comm-edu vol 2 (2), 150-152.

Syamsu, Y. (2009). PROGRAM BIMBINGAN DAN KONSELING DI SEKOLAH. bandung: Rizqi Perss.

Syarif, I. (2012). PENGARUH MODEL BLENDED LEARNING TERHADAP MOTIVASI DAN PRESTASI BELAJAR SISWA SMK. jurnal vokasi vol 2 (2), 336-349. 